\title{
BIMBINGAN TEKNIS (BIMTEK) KARYA TULIS ILMIAH BAGI GURU-GURU SD
} SE-KECAMATAN MIOMAFFO BARAT

\author{
Vinsensia Ulia Rita Sila ${ }^{1)^{*}}$, Oktovianus $\mathrm{Mamoh}^{2)}$, Martinus Lafu Salu ${ }^{3)}$ \\ Program Studi Pendidikan Biologi, Pendidikan Matematika dan Pendidikan Bahasa Inggris, \\ Fakultas Ilmu Pendidikan, Universitas Timor, Indonesia ${ }^{1), 2), 3)}$ \\ Pos-el: rincesila@gmail.com ${ }^{1)}$, oktomamoh01@ gmail.com ${ }^{2)}$, Martinuslsalu@ gmail.com ${ }^{3)}$ \\ *Corresponding author
}

\begin{abstract}
ABSTRAK
Untuk memenuhi tuntutan pengembangan profesionalisme siapapun dia yang dinamakan guru harus mampu membuat karya tulis ilmiah. Salah satu jenis penelitian yang dapat dilaksanakan oleh guru adalah Penelitian Tindakan Kelas (PTK). Tujuan dari kegiatan pengabdian ini adalah dapat membantu guru-guru SD Se-Kecamatan Miomaffo Barat dalam menyusun karya tulis ilmiah PTK. Kegiatan dilaksanakan di SDK Eban I, Kecamatan Miomaffo Barat pada tanggal 09 Agustus 2018 sampai dengan tanggal 11 Agustus 2018 dengan peserta 33 orang. Metode yang digunakan adalah metode survey, ceramah, tanya jawab, diskusi dan latihan. Data awal menunjukkan bahwa guru-guru sangat membutuhkan bimbingan teknis karya tulis ilmiah dengan memberikan respon positif sebesar $87,88 \%$. Sedangkan hasil yang diperoleh pada saat pelaksanaan kegiatan adalah guru-guru sudah mampu mengidentifikasi masalah, merumuskan judul dan menulis proposal PTK. Sebagai tanggapan atau respon terhadap terlaksananya kegiatan, maka peserta memberikan respon positif sebesar $81,82 \%$ pada aspek setelah mendapatkan materi PTK saya akan berusaha menulis proposal dan laporan hasil PTK. Dengan demikian, disimpulkan bahwa guru-guru SD-sekecamatan Miomaffo Barat sangat membutuhkan materi penulisan karya tulis ilmiah PTK, guru-guru SD-sekecamatan Miomaffo Barat sudah mampu mengidentifikasi masalah, merumuskan judul dan menulis proposal PTK dan guru-guru SD-sekecamatan Miomaffo Barat akan berusaha menulis proposal PTK dan laporan PTK setelah mendapatkan materi PTK.
\end{abstract}

Kata kunci: Karya tulis ilmiah, PTK, Guru SD, SDK Eban I

\section{ABSTRACT}

To meet the professional development, a teacher needs to compose a scientific writing. One type of scientific writing a teacher can generate is Classroom Action Research. The purpose of this Service Research is that to help primary teachers in the sub-district of Miomaffo Barat in writing the Classroom Action Research.

This activity was held in the primary school of SDK Eban 1, sub-district of Miomaffo Barat from 09 August 2018 to 11 August 2018 with the participant of 33 persons. The methods used in this research were surveying, lecturing, questioning, discussing and exercising.

The initial data showed that the teachers really needed a technical guidance about scientific writing by giving the positive response of $87.88 \%$. Meanwhile, data found during the research showed that the teachers were able to identify the problems, formulate the title and compose the proposal for the Classroom Action Research. As the response to the activity that has been done there, the teachers gave positive response of $81,82 \%$ in the aspect of "after attending the activity about Classroom Action Research, I will try to write my own proposal.” 
In conclusion, the primary teachers in the sub-district of Miomaffo Barat extremely need the technical guidance about how to write a scientific writing of Classroom Action Research. They also already have the knowledge about how to identify the problems, formulate the title and write a proposal of Classroom Action Research. Moreover, they would try to write a proposal as well as the report for Classroom Action Research.

Keywords: Scientific Writing, Classroom Action Research, Primary Teachers, SDK Eban I.

\section{PENDAHULUAN}

Kebutuhan akan karya tulis ilmiah oleh guru-guru pada setiap jenjang pendidikan baik guru sekolah dasar, guru sekolah menengah pertama dan guru sekolah menengah atas bahkan guru taman kanak-kanak cukup tinggi. Kebutuhan akan karya tulis ilmiah ini sangat dituntut sesuai dengan tuntutan perkembangan dunia pendidikan terkini sebagai salah satu kegiatan pengembangan profesi guru. Tujuan dari kegiatan pengembangan profesi guru adalah guru akan terdorong untuk menulis, meneliti dan mengemukakan pendapat. Dengan menulis berarti guru akan banyak membaca dan menyerap informasi sehingga akan meningkatkan kemampuan profesionalnya ( Takari, 2008).

Untuk memenuhi tuntutan profesionalisme guru ini maka, siapapun dia yang dinamakan guru terkecuali guru-guru yang masa kerjanya mendekati masa pensiun harus mampu membuat karya tulis ilmiah. Keharusan ini nampak semakin serius ketika pemerintah mengeluarkan UU No.14 tahun 2005 tentang Guru dan Dosen. Undang-Undang ini disusul dengan Peraturan Pemerintah No.19 tahun 2006 tentang Standarisasi Pendidikan. Belakangan ini, Menteri Negara Pendayagunaan Aparatur Negara juga mengeluarkan Peraturan Pemerintah. Peraturan Pemerintah yang dimaksud adalah No.16 tahun 2009 tentang Jabatan Fungsional Guru dan angka kreditnya.

Angka kredit adalah angka yang diberikan berdasarkan prestasi yang telah dicapai oleh seorang guru. Simbol angka kredit mencerminkan penilaian kualitas profesional guru. Jabatan dan pangkat seorang guru mencerminkan bobot kualitas profesional seorang guru. Sistem angka kredit telah dikembangkan sejak tahun 1980 berdasarkan pada Peraturan pemerintah No.3 tahun 1980, KEPMENPAN No.26 tahun 1989 dan diubah dengan KEPMENPAN No.84 tahun 1993, dan dijabarkan dalam SKB Mendikbud dan BKN No.433/P/1993 dan No.25 tahun 1993, serta Juknis Mendikbud No.025/O/1995. Adapun butir-butir sebagai bidang dan unsur kegiatan penilaian angka kredit guru adalah pendidikan, proses belajar 
mengajar dan pengembangan $80 \%$, sedangkan penunjang dan pengabdian pada masyarakat $20 \%$ (Takari, 2008).

Salah satu jenis penelitian yang mudah dilaksanakan dan mudah dalam penilaian angka kredit poin bagi guru adalah Penelitian Tindakan Kelas (PTK). Oleh karena itu seorang guru harus melaksanakan Penelitian Tindakan Kelas (PTK). Penilaian terhadap karya tulis ilmiah berupa PTK dilakukan secara berjenjang. Guru dengan pangkat/golongan III hanya dibutuhkan proposal PTK atau laporan hasil PTK. Sedangkan guru dengan pangkat/golongan IVa ke IVb dibutuhkan karya tulis ilmiah yang sudah dipublikaskan di jurnal.

Penelitian tindakan kelas ( PTK) adalah salah satu jenis penelitian tindakan yang dilakukan oleh guru untuk meningkatkan kualitas pembelajaran dikelasnya yang meliputi metode, pendekatan, penggunaan media, teknik evaluasi, dsb (Ahmad Jaedun, 2008 dalam Rahmawati, 2008). Penelitian tindakan kelas merupakan penelitian yang bersifat kasuistik dan berkonteks pada kondisi, keadaan dan situasi yang ada didalam kelas yang dilaksanakan untuk memecahkan permasalahan-permasalahan yang terjadi guna meningkatkan kualitas pembelajaran didalam kelas (Rahmawati, 2008). Tujuan dari pelaksanaan PTK adalah 1) Memperbaiki mutu dan praktik pembelajaran yang dilaksanakan guru demi tercapainya tujuan pembelajaran, 2) Memperbaiki dan meningkatkan kinerja-kinerja pembelajaran yang dilaksanakan oleh guru, 3) Mengidentifikasi, menemukan solusi dan mengatasi masalah pembelajaran dikelas agar pembelajaran bermutu, 4) Meningkatkan dan memperkuat kemampuan guru dalam memecahkan masalah-masalah pembelajaran dan membuat keputusan yang tepat bagi siswa dan kelas yang diajarnya (Sukanti dan Ani, 2008 dalam Rahmawati, 2008).

Berdasarkan pengalaman salah satu anggota tim penulis yang melakukan pengabdian masyarakat pada dua tahun terakhir tentang pelatihan penulisan proposal PTK bagi guru-guru SDN Noebesi (2016) dan bagi guru-guru SDN Tubmanu Saenam (2017) menunjukkan bahwa banyak guru belum mampu membuat karya tulis ilmiah mulai dari menyusun proposal PTK sampai pada menyusun hasil penelitian dengan alasan yang bervariasi. Namun dari pengalaman tim penulis saat melakukan pelatihan, ternyata menulis proposal saja, masih sangat sulit dalam menentukan masalah, mengidentifikasi masalah sampai pada menawarkan solusi masalah tersebut.

Kegiatan pengabdian yang dilakukan pada kesempatan ini meliputi tiga disiplin ilmu yang berbeda, yaitu dari ilmu pendidikan biologi, bahasa dan matematika. Pengabdian lintas disipliner ilmu ini dimaksudkan agar setiap bidang ilmu ini dapat menyumbangkan ilmu, mengabdikan ilmunya untuk membantu membuka wawasan para guru SD se-kecamatan Miomaffo Barat untuk dapat membuat proposal penelitian dan bahkan dapat membuat laporan penelitian.

Tujuan dari pengabdian antar disipliner ilmu ini agar dapat membantu para guru, menuntun, membimbing dari berbagai bidang ilmu sesuai dengan bidang para nara sumber. Dengan adanya pengabdian antar disipliner ilmu ini diharapkan agar memberikan solusi atas masalah yang dihadapi para guru.

\section{METODE}

Kegiatan pengabdian dilaksanakan di SDK Eban I, Kecamatan Miomaffo Barat pada tanggal 09 Agustus 2018 sampai dengan tanggal 11 Agustus 2018 dengan jumlah peserta 33 orang. Metode yang digunakan adalah a) metode survey dan observasi, digunakan untuk memperoleh gambaran kebutuhan guru-guru SD Se-kecamatan Miomaffo Barat akan penulisan karya ilmiah PTK, peserta dan lokasi pelaksanaan kegiatan, b) metode ceramah dan tanya jawab, digunakan pada saat menyampaikan materi PTK yang sifatnya teoritis dan c) metode diskusi dan latihan, digunakan pada saat tahap diskusi setelah penyampaian materi, latihan penulisan proposal PTK dan penulisan laporan PTK. 


\section{HASIL DAN PEMBAHASAN}

Karya tulis ilmiah (KTI) merupakan bagian utama dari kegiatan pengembangan profesi guru sebagai pendidik yang profesional yang kebutuhannya sangat dituntut sesuai dengan tuntutan perkembangan dunia pendidikan. Untuk memenuhi tuntutan profesionalisme tersebut siapapun dia yang dinamakan guru harus mampu membuat karya tulis ilmiah.

Salah satu jenis penelitian yang mudah dilaksanakan oleh guru adalah Penelitian Tindakan Kelas (PTK). PTK merupakan jawaban dari masalah yang terjadi dikelas yang dicari solusinya melalui penelitian. Hal ini sejalan dengan hasil yang diperoleh dari pengisian angket oleh setiap peserta sebelum kegiatan pengabdian bahwa guru-guru memberikan respon positif pada aspek karya tulis ilmiah sangat dibutuhkan demi pengembangan profesionalisme guru sebesar $87,88 \%$.

Hasil yang diperoleh dari kegiatan pengabdian adalah guru-guru peserta kegiatan pengabdian sudah mampu mengidentifikasi beberapa masalah antara lain alat bantu atau media pembelajaran yang digunakan guru belum memadai, siswa belum lancar membaca, siswa sulit menyelesaikan soal-soal operasi hitung pecahan, kurangnya alat praktek,kurangnya sarana/prasarana, kurikulum yang selalu berubah-ubah, metode yang digunakan guru belum bervariasi, minat baca siswa kurang dan ekonomi keluarga kurang mendukung. Selain itu juga dapat merumuskan beberapa judul yakni 1) Penggunaan kartu huruf dalam meningkatkan minat baca siswa kelas IV SDK Seoam II, 2) upaya peningkatan hasil belajar IPA siswa kelas V SDN Sa'tab dengan menggunakan media pembelajaran, 3) penerapan metode problem solving untuk meningkatkan hasil belajar siswa SDK Eban I pada materi pecahan dan satu proposal PTK yakni upaya peningkatan hasil belajar IPA siswa kelas V SDN Sa'tab dengan menggunakan media pembelajaran. Sebagai tanggapan atau respon terhadap terlaksananya kegiatan, maka peserta memberikan respon positif sebesar $81,82 \%$ pada aspek setelah mendapatkan materi PTK saya akan berusaha menulis proposal dan laporan hasil PTK. Hal ini menunjukkan bahwa para guru sangat membutuhkan bimbingan secara teknis tentang PTK sebagai pengembangan profesionalisme guru yang kualitasnya akan tercermin melalui jabatan dan pangkat seorang guru.

\section{SIMPULAN}

Simpulan dari kegiatan pengabdian ini adalah :

1. Guru-guru SD-sekecamatan Miomaffo Barat sangat membutuhkan materi penulisan karya tulis ilmiah PTK demi pengembangan profesionalisme guru, yang ditunjukkan dengan memberikan respon positif sebesar $87,88 \%$ melalui pengisian angket sebelum pelaksanaan kegiatan pengabdian

2. Guru-guru SD-sekecamatan Miomaffo Barat sudah mampu mengidentifikasi masalah, merumuskan judul dan menulis proposal PTK

3. Guru-guru SD-sekecamatan Miomaffo Barat akan berusaha menulis proposal PTK dan laporan PTK setelah mendapatkan materi PTK melalui kegiatan ini. Hal ini ditunjukkan dengan memberikan respon positif melalui pengisian angket sebesar $81,82 \%$.

\section{UCAPAN TERIMA KASIH}

Ucapan terima kasih ditujukan kepada LPPM Universitas Timor melalui Hibah Pengabdian Tahun Anggaran 2018.

\section{DAFTAR PUSTAKA}


Arikunto,S, Suhardjono dan Supardi.2015. Penelitian Tindakan Kelas. Jakarta: Bumi Aksara. Kementerian Pendidikan Nasional. 2006. Peraturan Menteri Pendidikan Nasional Nomor 22 Tahun 2006 tentang Standar Isi

Mamoh, O dan Kelen, Y. 2016. Laporan Pelatihan Penulisan Proposal PTK Bagi GuruGuru SDN Noebesi.LPPM Unimor.

Rahmawati,D. 2008. Makalah pelatihan penelitian dan penulisan karya ilmiah bagi guru akuntansi sekabupaten Sleman.

Takari, E.2008. Penelitian Tindakan Kelas. Bandung: PT. Genesindo 